\title{
Models and modelling for authentic STEM education: reinforcing the argument
}

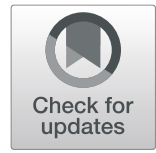

\author{
Jonas Hallström ${ }^{1 *}$ (D) and Konrad J. Schönborn²
}

\begin{abstract}
This commentary expands the notion that models and modelling can be used as a basis to foster an integrated and authentic STEM education and STEM literacy. The aim is to synthesize key publications that document relationships between authenticity, models and modelling, and STEM education. The implications of the synthesis are as follows: authenticity must be viewed as a cornerstone of STEM literacy; models and modelling processes can bridge the gap between STEM disciplines through authentic practices; models and modelling should be used as a means to promote STEM literacy and the transfer of knowledge and skills between contexts, both in and out of the STEM disciplines; modelling activities can serve as a meaningful route toward authentic STEM education; teaching authentic modelling processes must be rooted in explicit and tested frameworks that are based on the practice of the STEM disciplines; and, authentic STEM education should be driven by developing interaction between STEM subjects in parallel with maintaining the integrity of each subject. If this vision is to be reinforced, it is of utmost importance that implementing any model-based authentic educational activities are underpinned by evidencebased frameworks and recommendations for teaching practice. It is therefore imperative that intended model-based pedagogies for STEM education classrooms are further researched, in order to contribute to an integrated STEM literacy.
\end{abstract}

Keywords: Authenticity, Models, Modelling, STEM education, STEM literacy

\section{Introduction and aim}

The last decade has witnessed several concerted movements towards an integrated science, technology, engineering, and mathematics (STEM) education philosophy (e.g. Peterman, Daugherty, Custer, \& Ross, 2017). Integrated STEM is typically invoked when discussing education policy, curricula and economic competitiveness, but the acronym has also become a cornerstone of education for so-called twenty-first-century skills. STEM as an educational enterprise has grown in importance during the past 10 years, particularly in the USA, UK, and other Anglo-Saxon countries (Banks \& Barlex, 2014; Barlex, 2011). Albeit so, criticism against STEM approaches has also been put forward and includes, for example, that it may lead to a conflation of science and technology, or that the "T" and the "E" often tend to be downplayed in favour of the "S" and the "M" (e.g. Bers, Seddighin, \& Sullivan, 2013; Sanders, 2009). Arguments

\footnotetext{
* Correspondence: jonas.hallstrom@liu.se

'Department of Social and Welfare Studies (ISV), Linköping University, 60174 Norköping, Sweden

Full list of author information is available at the end of the article
}

have consequently also been put forward for a completely discipline-based STEM education (Henderson et al., 2017). There is therefore a certain vagueness around the actual concepts of STEM, and Pitt (2009) notes that:

Some people define any activity that involves any of science, technology, engineering or mathematics as a STEM activity; others argue that intrinsic to the concept is some linking of two or more of the component areas of learning, and that real STEM must be more than the sum of its parts (p. 41).

The root of this ambiguity arises from the fact that science, technology, engineering and mathematics as disciplines are not necessarily connected in neither content nor pedagogy (e.g. Tang \& Williams, 2018). Therefore, a great challenge for teachers in STEM subjects is to design classroom activities that integrate two or more of the subjects in their teaching in both a meaningful and relevant way (Bell, 2016; de Vries, 2017; Kertil \& Gurel, 2016; Margot \& Kettler, 2019; Radloff \& Guzey, 2016). In short, STEM teaching needs to be authentic (cf. 
Williams, 2017), and, in Pitt's words, "more than the sum of its parts".

In recent years, models and modelling has been argued as a means to increase relevance and authenticity in the STEM disciplines (e.g. Banks \& Barlex, 2014; France, 2018; Gilbert, 2004; Herrington, Reeves, \& Oliver, 2010; Justi \& Gilbert, 2002; Kertil \& Gurel, 2016; Rau, 2017; Turnbull, 2002). This is not only because modelling is central to the disciplines themselves as authentic practice in laboratories and workshops (Roth, 1995), but also since modelling is considered a fundamental aspect of STEM instruction. Two decades ago, Gilbert, Boulter, and Elmer (2000) flagged the importance of modelling and models in pursuing an authentic science and technology education, in lucidly stating that:

'Authentic' educations in science and technology must reflect the natures of the parent disciplines as far as is practicable. Modelling and models are common to both, thus providing a potential bridge between science education and technology education. [...] The purpose of modelling in both fields is to facilitate communication through a visualisation of the relation between the intention and the outcome of the activity (p. 3, 17).

As part of the same cogent line of thinking, Davies and Gilbert (2003) also argued that models and modelling could forge natural links between STEM disciplines such as science and design and technology, due to certain similarities in modelling practices. For example, in chemistry and physics, both teachers and students utilize various atomic models, and in technology and engineering, conceptual and physical models are used to represent and test various designs. Through processes of modelling in STEM education, the disciplines become bound by a synergistic relationship, often requiring a learner to transit between the learning areas while engaging scientific, mathematical and technological activities, which often render these processes interdependent (Gilbert et al., 2000).

We are aware of the accepted importance of models and modelling in STEM education literature, but at the same time assert that there is limited prior research on the nature of modelling as a bridge between STEM disciplines. Therefore, this commentary expands upon the position that models and modelling can be used as a basis to foster an integrated and authentic STEM education and STEM literacy. In reinforcing this argument, the aim is to synthesize key publications that document relationships between authenticity, models and modelling, and STEM education. We conclude by providing implications of the presented contributions for STEM education, across all the four disciplines.

\section{Authentic learning as a key component of STEM education and STEM literacy}

Science, technology, engineering, and mathematics as practices have been dependent on one another for centuries, which could account for the common conflation of them in public discourse. The evolution of modern science from the 16th and 17th centuries onward was largely dependent on the parallel development of instruments and laboratory equipment (Ihde, 1993). Galilei's telescope is one explicit example of what we could term, together with Ropohl (1997), science as "applied technics" (p. 66), while Newton's laws were penned in the "language" of mathematics. Conversely, modern technological development is equally unthinkable without its connection to science, for example, in industrial laboratories and in modern genetic engineering and nanotechnology (de Vries, 2001; Feenberg, 2006). However, from an epistemological point of view, these disciplines constitute different fields of knowledge, because a scientist studies nature to uncover its laws, whereas the technologist and engineer solve problems with workable technological solutions. Mathematicians, in turn, aid both scientists and technologists with the analytical tool of mathematics. The previously mentioned equivocalness between the subject-specific and the interdisciplinary aspects of STEM may in part emanate from the fact that although science, technology, engineering and mathematics are separate epistemological fields, they are closely related in scientific and engineering practice, not only historically, but particularly today (cf. Pitt, 2009).

With reference to an Australian national curriculum document, Williams (2017) points to another built-in ambiguity of STEM literacy. STEM literacy should relate both to goals of national economic growth and the development of the individual student in terms of acquiring knowledge, attitudes and skills to identify real-world problems through an understanding of the characteristic features of the STEM subjects. In other words, the concept has both vocational and general educational connotations (Williams, 2017). We argue that in terms of educational settings, STEM literacy aims for general educational goals, but that these goals need to address authentic issues by incorporating two or more of the STEM disciplines (Sanders, 2009). Incorporation should not be understood as creating mere mergers between science, technology, engineering and mathematics but rather as an interdisciplinary cooperation on equal terms, which considers the central epistemological concerns of each discipline as well as the rich historical heritage and common concepts and practices.

Designing authentic learning scenarios is therefore one of the key challenges in education interventions that aim for STEM literacy (Ciolan \& Ciolan, 2014). Although the concept of authenticity is ubiquitous, it is also contested 
(Anker-Hansen \& Andreé, 2019). In this commentary article, we adhere to a socio-cultural conception of authenticity where it is defined as students' participation in practices and activities of professional scientists and technologists, or activities appropriate for, or corresponding closely to these (see Murphy, Lunn, \& Jones, 2006). According to Herrington and Parker (2013), the key elements of authenticity comprise an authentic context, an authentic task, the presence of expert performances, multiple perspectives, collaboration, reflection, articulation, metacognitive support and authentic assessment. Previous research on authentic learning in science and technology education has focused on several of these elements, such as the importance of creating an authentic context for performing authentic assessment, and the relevance of modelling for authentic technology education (e.g. Bulte, Westbroek, de Jong, \& Pilot, 2006; Fox-Turnbull, 2006; Svärd, Schönborn, \& Hallström, 2017). Thus, authentic learning often concerns the central concepts, principles, and practices in a discipline, or across several cooperating disciplines.

\section{Models and modelling for authentic STEM education and STEM literacy}

As pointed out by Gilbert and colleagues (e.g. Gilbert et al., 2000; Justi \& Gilbert, 2002), models and modelling play a central role in science and technology education. In a recent commentary on a conceptual framework for integrated STEM education in this journal, Kelley and Knowles (2016) unpack a comparison of science and engineering practices from the National Research Council (NRC) in the USA. Herein, models feature as a salient aspect of both practices and include using models to "develop explanations about natural phenomena" in science, while using models to "analyse existing solutions" in engineering. Furthermore, the same essay also identifies mathematical models and modelling thinking as central to developing design solutions before prototyping stages in engineering practice. It follows, that discussing the notion of an authentic STEM education relies heavily on considering the pivotal functions of models and modelling. Models and modelling are important tools for problem solving, prediction, decision making, and communication and have been studied and analysed in the history, philosophy, and sociology of science and technology, and in the engineering sciences (e.g. Müller, 2009; Vincenti, 1990). Moreover, the important relationship between mathematical modelling and authenticity as a social construct has been pointed out by Vos (2011). Models simplify aspects of reality and range from simple conceptual sketches and rough prototypes to advanced mathematical models. Models in engineering are largely defined in functional terms. For example, where friction or gravity can often be ignored in the modelling of multiple phenomena in the natural sciences, this is not the case in real engineering settings (Hansson, 2007, 2013).

Their application in prediction is the major quality of engineering models, as they are used to predict whether future innovations, processes or systems shall be able to perform intended functions. Prediction requires correlation, but not necessarily a causal connection. This means that the demands on models for prediction are lower than on scientific models that strive to be useful for explanation of natural phenomena (cf. Scriven, 1988). Engineering models are also used to facilitate communication and to illustrate problems and principles. One of the core communication capabilities of the engineering community is to use graphical representations of objects and processes in the form of sketches, drawings, diagrams and charts (Ferguson, 1992; Mitcham, 1994). Therefore, the ability to create, use/apply, evaluate and revise models are necessary skills for acquiring an in-depth understanding of both technological development processes and scientific practice and are a core component for pursuing authentic learning in technology, mathematics and science classrooms (Schwarz et al., 2009).

Whereas models and modelling are an integral and well-researched aspect of science, mathematics, and to a certain extent engineering education (Justi \& Gilbert, 2002; Lesh, English, Sevis, \& Riggs, 2013; Vos, 2011; Zawojewski, Hjalmarson, Bowman, \& Lesh, 2008), only a few technology education research studies and writings have focused on the explicit role of models and the modelling process. Examples of work include that by Gilbert et al. (2000), France, Compton, and Gilbert (2011), Haglund and Strömdahl (2012), and Nia and de Vries (2017). Gilbert (2004) distinguishes between five different representational modes of models: the concrete or material; the verbal; the symbolic; the visual; and the gestural. This diversity of representational modes must be taken into consideration when developing authentic STEM education interventions, although each of these modes possesses relative "representational power" as well as limitations. There is a high potential application of symbolic, visual as well as physical models in technology education. Discerning and interrogating a model's strengths and weaknesses are conducive to solving realworld authentic tasks.

The main argument underpinning this commentary is that a successful integration of two or more STEM disciplines is dependent on authentic concepts or practices as a bridge. We hereby reinforce the role of models and modelling as such an authentic bridge across STEM education, also strongly motivated by earlier workers such as Gilbert (2004) who argued that "a central role for models and modelling would greatly increase the 
authenticity of the science curriculum" (Gilbert, 2004, p. 115). At the same time, if the means for teaching modelling processes is to be authentic, then this must be founded on conceptual frameworks that reflect the practice of science itself (Justi \& Gilbert, 2002). If we extrapolate this argument to the STEM disciplines, it follows that integration of science, technology, engineering and mathematics could be greatly enhanced by operationalising the influence, functions and implications of models and modelling.

Modelling in the form of visual representations is one way of operationalising because it is both authentic and serves a crucial role in supporting learning in science, technology, engineering and mathematics (Rau, 2017). Such representations are often in the form of externalised visual models, where the interpretation and use of models is common and often a central practice in STEM domains. Indeed, instruction relies heavily on modelling concepts and processes in science, technology, engineering and mathematics. For example, in a science domain such as chemistry, in order to understand how atoms bond to form molecules, it is necessary for students to interpret and interrogate models that represent how individual atoms participate in bonding (e.g. Lewis structure models), consequent bond angles in 3D space (e.g. ball-and-stick models), as well the associated molecular volume (e.g. space-filling models). In a technology education domain, models related to the drawing or visuospatial manipulation and representation of an artefact or design process are often engaged. For example, if secondary students design a house in technology class, they might begin with producing a 3D model in CAD (computer-aided design) software, continue with utilizing mathematical models for calculating dimensions of loadbearing structures, and, finally, build a physical prototype. Furthermore, in a mathematics domain, various models are used to highlight different conceptual interpretations of fractions, for example. According to Rau (2017), such models include "area models that help students understand equipartitioning and parts-of-a-whole concepts (e.g., pie chart, rectangles), linear models that highlight measurement concepts (e.g., fraction strips, number lines), and discrete models that emphasize ratio interpretations (e.g., sets, counters)" (Rau, 2017, p. 746; cf. Lesh, 1981; Lesh, Post, \& Behr, 1987). Tang and Williams (2018) view visual modelling as a common literacy skill in STEM, although they also caution that visual representations may be specific to a particular field.

According to Rau (2017), it follows that from a sociocultural point-of-view, learning of representational and associated modelling competencies:

[...] first manifest in social interactions, which then become internalized [...] Through social interactions with a more knowledgeable person (e.g., teacher, another student, parent), students learn how to use visual representations in authentic tasks. During this process, students often start by observing experts and may then use visual representations themselves with the support of the more knowledgeable person. With increasing experience, this support is faded out and students take on increasing responsibility for solving authentic tasks themselves. Thus, participation in community practices is a critical socially mediated mechanism through which students acquire representational competencies (Rau, 2017, p. 724).

Rau (2017) thus points to the importance of operationalising a modelling pedagogy for the STEM disciplines, although few attempts have been made to do so. As motivated above, all the STEM disciplines engage with modelling and yet struggle with authenticity. To the authors' knowledge, no synthesis of the literature has yet been conducted on the nature and role of models and modelling across the STEM disciplines as a whole. In response, Table 1 presents fifteen key STEM education contributions, related to the role of models and modelling as a means of bridging STEM disciplines in pursuit of authentic STEM education.

A number of different model uses and modelling processes and skills are proposed by the contributions referred to in this commentary, but we focus on those related to authentic practices and skills for an integrative STEM education. Based on the overview presented in Table 1, we offer the following three assertions about the role and functions of models and modelling for pursuing authentic STEM education:

Firstly, our STEM community requires a definition and classification of the nature of model types and model uses and components of the modelling processes. Although models and modelling differ slightly between the STEM disciplines, there are some clear similarities, for example, concerning visual models and representations (e.g. Tang \& Williams, 2018). Exploring these similarities and bridging differences could strengthen STEM education and STEM literacy. In this regard, Nia and de Vries (2017) have proposed a framework for the "dual nature" (cf. de Vries \& Meijers, 2013) of models, which could in principle be applied across the STEM disciplines. They describe the "intrinsic" nature of models as concerning the material structure and form of models, whereas the "intentional" nature of models concerns their functions, that is, whether they are used for exploration, design or communication. In line with Nia and de Vries (2017), Table 1 infers that modelling is often about representing simplified versions of reality that take on concrete/physical, conceptual, verbal, gestural or symbolic/mathematical forms (Gilbert, 2004). Models are 
Table 1 Roles, functions, strategies and recommendations for using models and modelling in pursuit of authentic STEM education and literacy

\begin{tabular}{|c|c|c|c|c|}
\hline $\begin{array}{l}\text { STEM area(s) and key } \\
\text { papers }\end{array}$ & $\begin{array}{l}\text { Definition of the nature of } \\
\text { models and components of } \\
\text { the modelling process }\end{array}$ & $\begin{array}{l}\text { Roles and functions of model } \\
\text { use in relation to specific } \\
\text { modelling processes and skills }\end{array}$ & $\begin{array}{l}\text { Strategies for teaching models } \\
\text { and modelling in authentic } \\
\text { STEM educational practice }\end{array}$ & $\begin{array}{l}\text { Recommendations for } \\
\text { integrating models and } \\
\text { modelling in authentic } \\
\text { STEM curricula and } \\
\text { programmes }\end{array}$ \\
\hline
\end{tabular}

\begin{tabular}{ll}
\hline Silbert (2004) & A model can exist in at \\
& least five modes of \\
& representation: concrete \\
& (e.g. 3D physical models), \\
& verbal (e.g. spoken or \\
& written description of \\
& model entities), symbolic \\
& (e.g. chemical formulae), \\
& visual (e.g. diagrams and \\
& animations), gestural (e.g. \\
& bodily representation of \\
& model entities).
\end{tabular}

S Justi and Gilbert (2002)

SD\&T Davies and Gilbert (2003)

SD\&T

Gilbert et al. (2000)
Modelling is the formation, expression, testing and revision of models. Scientific models can comprise consensus models (used in research) or historical models (replaced by revised models over time).

A model represents an object, idea, system, event, or process in different modes of representation. In science education modes often include concrete, visual, verbal, mathematical, or gestural representations. In technology education modes often include iconic (e.g. a sketch), analogue (e.g. simulation), and symbolic (e.g. mathematical) models.
Understanding what a model is, understanding the entities that a particular model represents and how these entities interact with each other, mentally visualizing models, displaying visual literacy skills associated with interpreting models, understanding analogy and metaphor in relation to describing model components, and understanding how a model can be used.

Models and modelling play a central role in learning science and learning how to do science. The modelling process includes ascertaining the purpose of the model, which often includes producing a mental model of the phenomenon, and deciding in what mode of representation (e.g. visual, verbal or mathematical) to express the model. While "testing" whether a model satisfies its intended purpose, the modeller deduces the scope and limitations of the model.

Two roles of modelling are modelling ideas in the mind (communicating with oneself) and modelling ideas in the world (communicating with others). The modelling process includes having experience of the phenomenon or problem, formulating suitable

metaphors and analogies to express the model, visualizing the outcome of the modelling process, producing a representation of the model, and evaluating the scope and limitations of the produced model.

Modelling components include mental models (cognitive representations), expressed models (available for others to interpret), consensus models (expressed models that gain acceptance), scientific models (tested expressed models that become predictive tools), historical models (exist in a context and perhaps later displaced),
To promote an authentic model-based teaching approach, science teachers need to show learners what representational 'entities' constitute a model; demonstrate the scope and

limitations of different models; select, develop or change model usage depending on the topic taught; and, design meaningful modelling activities that involve learners' active model construction.

Promote the following modelling strategies during teaching: convey the purpose of a particular model or modelling activity, provide a meaningful experience of the phenomenon being modelled during any practical work, explicitly describe the source from which a particular model arises, support the mental visualization of a particular model, and show how different modes of representation making up different models of a phenomenon are related.

Teach modelling strategies for learners to develop a mental image of a model, realise that a model can exist in multiple modes, ascertain that models comprise entities for conveying concepts, understand that a model helps to make predictions or solve a problem, take cognisance that a model's value is determined by a community, comprehend that a model is open to modification, and discover that models exist as a historical sequence of different expressions.

Teaching models and modelling contributes to science learning since mental modelling is central to understanding; expressing and testing models reflects the 'doing' of science and understanding science relies on interpreting scientific and historical models. Modelling in science and technology both involve a developmental cycle
Integrating models and modelling can increase the authenticity of STEM curricula by explicitly training science teachers in the nature and role of models. Integrating models and modelling in STEM curricula can be promoted through pupils learning to use models, revise models, reconstruct models, and construct models de novo.

Pre- (and in-) service STEM education should focus heavily on unpacking the nature of a 'model', how to use different models in different contexts (transfer), following the historical sequence of model development in a certain topic area as a means of cognitive reconstruction in modelling, and providing skills for evaluating the strengths and limitations of models.

Implementing models and modelling to promote authentic learning that embraces both science and technology education requires realising the importance of the learner's context. This means that approaches and curricula need to be purposeful, cogent, and personally meaningful. Doing so will allow learners to perceive relationships between science and technology content while applying knowledge in finding solutions to real problems.

Models and modelling should be viewed by educators and curriculum developers as a valuable bridge between science and technology, which in turn, may promote authentic STEM education and an opportunity to develop activities to find solutions to, and make informed decisions, about 
Table 1 Roles, functions, strategies and recommendations for using models and modelling in pursuit of authentic STEM education and literacy (Continued)

\begin{tabular}{llll}
\hline STEM area(s) and key & $\begin{array}{l}\text { Definition of the nature of } \\
\text { papers } \\
\text { models and components of } \\
\text { the modelling process }\end{array}$ & $\begin{array}{ll}\text { Roles and functions of model } \\
\text { mode in relation to specific }\end{array}$ & $\begin{array}{l}\text { Strategies for teaching models } \\
\text { and modelling in authentic }\end{array}$ \\
& & modeling processes and skills & STEM educational practice
\end{tabular}

Recommendations for integrating models and modelling in authentic STEM curricula and programmes

representations of an idea, system, event, or process.

SEM

Zawojewski et al. (2008); Diefes-Dux, Hjalmarson, Miller, and Lesh (2008).

TE de Vries (2013)

STE

Nia and de Vries

(2017); de Vries

(2013)

ST

France et al. (2011): France (2018) to knowledge building: they provide explanations
Models for making sense of or learning about complex systems consist of hardware (one-way cause-and-effect relationships), software than the 'sum of the parts') and wetware (neurochemical, fuzzy interactions in complex, dynamic systems).

Models are a development of a simplified version of reality and can include concrete, conceptual, and formal/symbolic models.

Models can be considered as "techno-scientific artefacts". They have an intrinsic nature (material structure of different models and types), intentional nature (development and communication of knowledge and artefacts in science and technology), as well as an intrinsic-intentional interrelation. (recursive interactions, more

curricular models (historical models in curricula), teaching models (aid interpreting historical and curricular models), and hybrid models (coordinate scientific, historical or curricular models).

Principles for model-eliciting activities include model construction, reality, selfassessment, model documentation, model shareability and re-usability, and producing an effective prototype.

here iterative changes are associated with the produced model, a fitness for purpose where a certain specification is envisioned, and a visualization of the intended outcome of the process.

Students should be provided with an opportunity to experience how mathematical models come to be and interrogate the trade-offs involved in developing a mathematical model, including assessing the limitations and strengths of different models. conceptual models, sketches).

Models in science are central Functional modelling concerns and predictions. Multiple consensus models of a phenomenon illustrate the
Models support the development of theories and artefacts through manipulation (e.g. concrete models) and mental exploration (e.g. Models communicate theories and artefacts through educational models and procedural models.

The intrinsic and intentional nature of models can support building, revising, and communicating knowledge and artefacts related to pedagogical use (e.g. educational models); procedural use (e.g. CAD models); and decisional use (e.g. risk-mitigation models). The intrinsic-intentional interrelation of models informs design (users' points of view), simplification (abstraction and idealization), iterativity (trial and error), and adequacy (judging appropriateness and effectiveness).

Combining modelling and design activities promotes STEM learning since design connects scientific, technological, engineering and mathematical elements. Also, modelling activities provide a bridge between a practical situation and required mathematical analytical tools to model different versions of reality. This is particularly the case in problems when understanding reality (science) and manipulating reality (technology and engineering) is envisioned.

The intrinsic, intentional and intrinsic-intentional perspective of models can inform teaching strategies about how to talk about the nature and uses of models and modelling in science, technology and engineering. the development of a design concept and prototyping of the realised outcome (often as a "thing"). Technological modelling provides epistemic
Developing students' conceptual understanding of modelling allows for an enhanced individual modelling ability. In this way, modelling can be used as a pedagogical

real-world issues by integrating both science and technology concepts.

Through implementing model-eliciting activities, students are potentially better positioned to understand the strengths and weaknesses of a conventional model, and better prepared to apply, adapt, and even create new mathematical models for novel and similar situations (e.g. across other STEM disciplines).

The encompassing facets of modelling allow it to be integrated at various points of pupil development in STEM curricula. For example, primary pupils can be provided with early experiences of modelling through concrete models. This could follow on to providing secondary pupils with formal aspects of modelling, which include nature, types and functions of models and modelling.

The intrinsic, intentional and intrinsic-intentional perspective of models can be used to analyse curricula and policy documents on the integration of models and modelling. The perspectives can be seen as a benchmark of what a curriculum should include regarding models and modelling in the STEM disciplines.

Modelling can support the development of an understanding of the nature of technology and the nature of science both as separate disciplines, but 
Table 1 Roles, functions, strategies and recommendations for using models and modelling in pursuit of authentic STEM education and literacy (Continued)

\begin{tabular}{lllll}
\hline $\begin{array}{l}\text { STEM area(s) and key } \\
\text { papers }\end{array}$ & $\begin{array}{l}\text { Definition of the nature of } \\
\text { models and components of } \\
\text { the modelling process }\end{array}$ & $\begin{array}{l}\text { Roles and functions of model } \\
\text { use in relation to specific } \\
\text { modelling processes and skills }\end{array}$ & $\begin{array}{l}\text { Strategies for teaching models } \\
\text { and modelling in authentic } \\
\text { STEM educational practice }\end{array}$ & $\begin{array}{l}\text { Recommendations for } \\
\text { integrating models and } \\
\text { modelling in authentic } \\
\text { STEM curricula and } \\
\text { programmes }\end{array}$ \\
\end{tabular}

\begin{tabular}{|c|c|c|c|c|}
\hline & $\begin{array}{l}\text { nature of science. Models in } \\
\text { technology help develop } \\
\text { technological knowledge } \\
\text { by building and manipulating } \\
\text { models. Models are used to } \\
\text { understand design concepts } \\
\text { and optimise prototypical } \\
\text { and functional artefacts. }\end{array}$ & $\begin{array}{l}\text { strategies for ensuring that the } \\
\text { technological outcome is "fit } \\
\text { for purpose". In technology, } \\
\text { the purpose is a designed } \\
\text { intervention where the } \\
\text { outcome is judged by a } \\
\text { successful function. In science, } \\
\text { the purpose is to explain } \\
\text { phenomena, where the } \\
\text { explanation is judged by an } \\
\text { ability to make sense of } \\
\text { empirical evidence. }\end{array}$ & $\begin{array}{l}\text { strategy to support } \\
\text { technological practice in } \\
\text { technology, as well as the } \\
\text { learning of concepts in } \\
\text { science. }\end{array}$ & $\begin{array}{l}\text { also in relationship with } \\
\text { one other. An understanding } \\
\text { of models and modelling in } \\
\text { technology and in science } \\
\text { can provide the learner with } \\
\text { the capacity to build bridges } \\
\text { between the two disciplines. }\end{array}$ \\
\hline $\begin{array}{l}\text { M } \\
\text { Niss (2012) }\end{array}$ & $\begin{array}{l}\text { A mathematical model can } \\
\text { be defined as the } \\
\text { indispensable combination } \\
\text { of an extra-mathematical } \\
\text { domain, a mathematical } \\
\text { domain, and the mapping } \\
\text { (translation) between the two. }\end{array}$ & $\begin{array}{l}\text { Mathematical modelling is the } \\
\text { selection, modification or } \\
\text { construction of a mathematical } \\
\text { model to describe an extra- } \\
\text { mathematical domain. A } \\
\text { mathematical modeller is the } \\
\text { person or entity that introduces } \\
\text { the model into the domain. }\end{array}$ & $\begin{array}{l}\text { Two observations need to be } \\
\text { noted for teaching practice. } \\
\text { Firstly, there is no automatic } \\
\text { transfer from mathematical } \\
\text { skills to models and modelling } \\
\text { skills. Secondly, effective } \\
\text { teaching of models and } \\
\text { modelling requires paying } \\
\text { concerted attention to the } \\
\text { design of activities, with } \\
\text { adequate time for the } \\
\text { activities to be realised. }\end{array}$ & $\begin{array}{l}\text { Take advantage of models } \\
\text { and modelling to support } \\
\text { students' concept formation } \\
\text { and sense-making in } \\
\text { mathematics, educational } \\
\text { interventions for promoting } \\
\text { authentic modelling skills } \\
\text { and competencies need } \\
\text { more than mere } \\
\text { presentation of stereotypical } \\
\text { examples on the } \\
\text { assumption that this will } \\
\text { automatically lead to } \\
\text { transfer, modelling requires } \\
\text { actively engaging and } \\
\text { promoting a suite of skills. }\end{array}$ \\
\hline $\begin{array}{l}\text { M } \\
\text { Brady, Lesh, and Sevis } \\
\text { (2015); Lesh, Amit, } \\
\text { and Schorr (1997); } \\
\text { Lesh et al. (2013) }\end{array}$ & $\begin{array}{l}\text { A model can be seen as a } \\
\text { system for describing, } \\
\text { explaining, constructing, } \\
\text { modifying, and predicting a } \\
\text { series of experiences. } \\
\text { Models help organise } \\
\text { relevant information to } \\
\text { generate or (re)interpret } \\
\text { hypotheses about } \\
\text { situations or events, explain } \\
\text { how information is related, } \\
\text { and make decisions based } \\
\text { on cues and information. }\end{array}$ & $\begin{array}{l}\text { Model-eliciting activities (MEAs) } \\
\text { include the reality principle (is } \\
\text { the situation authentic?), } \\
\text { model construction principle } \\
\text { (is the construction or } \\
\text { modification of a model } \\
\text { required?), self-evaluation } \\
\text { principle (are there clear } \\
\text { criteria for assessing the } \\
\text { usefulness of the model?), } \\
\text { model generalization principle } \\
\text { (does the model apply to } \\
\text { multiple situations?), and } \\
\text { simple prototype principle (will } \\
\text { the solution provide a useful } \\
\text { prototype for interpreting } \\
\text { other similar situations?). }\end{array}$ & $\begin{array}{l}\text { In relation to models and } \\
\text { modelling, mathematical } \\
\text { knowledge and abilities can } \\
\text { be developed along various } \\
\text { dimensions that include from } \\
\text { concrete to abstract, from } \\
\text { specific to general, from global } \\
\text { to refined, or from intuitions to } \\
\text { formalisations. When students } \\
\text { engage in model-eliciting } \\
\text { activities to assess and monitor } \\
\text { their own work using authentic } \\
\text { tools, they induce the } \\
\text { construction, modification } \\
\text { and refinement of powerful } \\
\text { conceptual models. }\end{array}$ & $\begin{array}{l}\text { Implementing models and } \\
\text { modelling in authentic } \\
\text { learning programmes can } \\
\text { help students construct, } \\
\text { modify and refine } \\
\text { conceptual models that are } \\
\text { applicable not only to } \\
\text { mathematics but also to } \\
\text { other modelling adaptation } \\
\text { activities in engineering } \\
\text { and science. }\end{array}$ \\
\hline
\end{tabular}

therefore simplified representations of phenomena that often include concrete entities that can be smaller or larger than the represented phenomenon. Models could also be abstractions such as force depictions or graphs or equations (Lesh et al., 1987). Models are therefore representations of ideas, objects, systems, events, or processes which are central in science, technology, engineering and/or mathematics. At a conceptual level, models are even systems of description in themselves, for explaining, constructing, modifying, manipulating and/or predicting a complex series of experiences. Models thereby help to organize relevant information so as to generate or (re)interpret hypotheses about given situations, events, designs or processes, or explain how information is related.

Secondly, the STEM community requires a classification of central functions of modelling processes and skills associated with models and modelling. Central functions of models are to support development of theories and artefacts through manipulation (e.g. concrete models) or mental exploration (e.g. conceptual models, sketches) (de Vries, 2013), and, in the latter case, modelling ideas in the mind for communicating with oneself and modelling ideas in the world for communicating 
with others (Davies \& Gilbert, 2003). Some of the primary skills associated with modelling include understanding what a model is and how to use it; carefully defining the context of the modelling process (i.e. is it a real-life or an educational context?); mentally visualizing a model outcome; deciding what mode of representation (e.g. physical, visual, verbal or symbolic/mathematical) to express the model in; and understanding how a model can be constructed, interpreted, tested/evaluated, revised and (re-)used. A crucial skill is also being able to evaluate the scope and limitations of a certain model. Nia and de Vries (2017, p. 647) further claim that students should learn about the relationship between the intrinsic and intentional/functional nature of models by taking both users' and designers' viewpoints into account:

- Users' view: Associated with understanding how a specific property of the model at hand makes it suitable for serving certain action(s). This understanding can occur in diverse ways such as direct learning about, reflecting upon, or testing ready-made models.

- Designers' view: Associated with how designers learn to produce useful models that realize their intended functions. To achieve such learning, students can be faced with various predefined functions regarding a model and be asked to develop their own, what they consider to be, relevant models. One may point in this regard to the example of asking students to conceptualize, construct, and/or discuss their graphical simulations of the design of a comfortable driver, passenger or baby car seat.

In such authentic design situations students will also "design" scientific and mathematical formulae and models to optimise their designs; new knowledge is developed about the design process itself but also about science and engineering, wherein students are required to apply existing knowledge previously learnt in science, technology and/or mathematics (Ammon, 2017; de Vries, 2018; Kertil \& Gurel, 2016).

Lastly, common to all four STEM disciplines is the fact that a model can exist in different modes of representation. The ability of students to switch and transit between various representational modes increases their potential for learning, not only of modelling itself but also about the central concepts and practices of the STEM discipline in question. Furthermore, knowledge about mode of representation also increases the potential of using the same model but in different contexts, which also augments the opportunity for interdisciplinary cooperation between the STEM disciplines.

\section{Conclusions and implications for STEM education}

Modelling is an authentic practice in science, technology, engineering and mathematics education (see e.g., Banks \& Barlex, 2014; Gilbert, 2004; Herrington et al., 2010; Turnbull, 2002) and therefore must be seen as a fundamental component of STEM literacy (cf. Williams, 2017). Even though this premise, in itself, is not a novel stance, recent studies have shown that STEM students possess more advanced "meta-modelling knowledge" than students of other, single disciplines at tertiary level (Krell \& Krüger, 2017), so there are evident advantages beyond strictly discipline-based for teaching and learning modelling as an aspect of an integrated STEM literacy. Thus, although models and modelling can thereby be construed as one of the core tools or "languages" of an integrative STEM literacy, more urgent educational research is needed on how modelling can be developed to meaningfully link the STEM disciplines.

We argued at the outset that the STEM disciplines are not necessarily related in either content or pedagogy. However, as described in this commentary, science, technology, engineering and mathematics become closely intertwined during authentic practice (e.g. de Vries, 2018; Hallström \& Ankiewicz, 2019; Kelley \& Knowles, 2016). There can be active linking and educational cooperation on an equal footing through modelling, although it is still crucial to distinguish between models for educational purposes and models as part of authentic practices. We suggest that Gilbert and colleagues' earlier initiated vision from 2000 not only applies to science and technology education but to the whole STEM education spectrum:

The nature of authentic education in science and (design and) technology has suggested that modelling and models should be taught across both fields as a way of linking them (Gilbert et al., 2000, p. 17).

The implications drawn from the synthesis presented in this commentary for STEM education are as follows:

- Authenticity must be viewed as a cornerstone of STEM literacy (e.g. Roth, 1995).

- Models and modelling processes can bridge the gap between STEM disciplines through authentic practices (e.g. France, 2018; Gilbert et al., 2000).

- Models and modelling should be used as a means to promote STEM literacy and the transfer of knowledge and skills between contexts, both in and out of the STEM disciplines (e.g. Niss, 2012).

- Modelling activities can serve as a meaningful route toward authentic STEM education (e.g. Davies \& Gilbert, 2003; Gilbert, 2004). 
- Teaching authentic modelling processes must be rooted in explicit and tested frameworks that are based on the practice of the STEM disciplines (e.g. Justi \& Gilbert, 2002), such as the approach provided by Nia and de Vries (2017).

- Authentic STEM education should be driven by developing interaction between STEM subjects in parallel with maintaining the integrity of each subject (Williams, 2011).

- Integrating science, technology, engineering and mathematics remains a complex challenge that calls for "a new generation of STEM experts" (Kelley \& Knowles, 2016).

- Authentic STEM education should focus on decreasing the vocational-and often politicisednotion of STEM as a way to increase economic competitiveness in favour of promoting STEM as an interdisciplinary way of learning authentic science, technology, engineering and mathematics (Pitt, 2009; Williams, 2011, 2017).

In conclusion, this commentary has reinforced the importance and implications of models and modelling in the promotion of an authentic STEM education. If this vision is to be realised, it is crucial that implementing any model-based authentic educational activities are underpinned by meaningful and evidence-based frameworks and recommendations for teaching practice (e.g. Kertil \& Gurel, 2016; Tang \& Williams, 2018). The contributions described in this commentary are central to each of the STEM disciplines and could be used to further operationalise potential recommendations for a broader STEM education mandate. It is also imperative that intended model-based pedagogies for STEM education classrooms are further researched and tested in real educational settings, in order to contribute to an integrated STEM literacy.

\section{Abbreviations}

CAD: Computer-aided design; MEA: Model-eliciting activity; NRC: National Research Council; STEM: Science, technology, engineering and mathematics

\section{Acknowledgements}

Not applicable.

\section{Authors' contributions}

The two authors contributed equally to the development and collaborative writing of the manuscript. Both authors read and approved the final manuscript.

\section{Authors' information}

$\mathrm{JH}$ is a professor of technology education in the Department of Social and Welfare Studies, Linköping University, Sweden. He directs the technology education research group of the Technology and Science Education Research unit (TESER) and also heads research development at the Swedish Centre for School Technology Education (CETIS).

KS is an associate professor (docent) of visualization and media technology in the Department of Science and Technology, Linköping University,
Sweden. He is also scientific leader of the Swedish National Graduate School in Science, Mathematics, and Technology Education (FontD).

Funding

The authors declare that there is no funding for this research.

\section{Availability of data and materials}

Data sharing not applicable to this article as no empirical datasets were generated or analysed during the current study.

\section{Competing interests}

The authors declare that they have no competing interests.

\section{Author details}

${ }^{1}$ Department of Social and Welfare Studies (ISV), Linköping University, 60174 Norrköping, Sweden. ${ }^{2}$ Department of Science and Technology (ITN), Linköping University, 60174 Norrköping, Sweden.

Received: 25 February 2019 Accepted: 13 June 2019

Published online: 28 June 2019

\section{References}

Ammon, S. (2017). Why designing is not experimenting: Design methods, epistemic praxis and strategies of knowledge acquisition in architecture. Philosophy \& Technology, 30, 495-520.

Anker-Hansen, J., \& Andreé, M. (2019). In pursuit of authenticity in science education. NorDiNa, Nordic Studies in Science Education, 15(1), 498-510.

Banks, F., \& Barlex, D. (2014). Teaching STEM in the secondary school: Helping teachers meet the challenge. London: Routledge.

Barlex, D. (2011). The STEM Programme in England. In M. J. de Vries (Ed.), Positioning Technology Education in the Curriculum. Rotterdam: Sense Publishers.

Bell, D. (2016). The reality of STEM education, Design and technology teachers' perceptions: A phenomenographic study. International Journal of Technology and Design Education, 26(1), 61-79.

Bers, M., Seddighin, S., \& Sullivan, A. (2013). Ready for robotics: Bringing together the T and E of STEM in early childhood teacher education. Journal of Technology and Teacher Education, 21(3), 355-377.

Brady, C., Lesh, R., \& Sevis, S. (2015). Extending the reach of the models and modelling perspective: A course-sized research site. In G. A. Stillman et al. (Eds.), Mathematical Modelling in Education Research and Practice (pp. 55-66). Dordrecht: Springer International Publishing.

Bulte, A. M. W., Westbroek, H. B., de Jong, O., \& Pilot, A. (2006). A research approach to designing chemistry education using authentic practices as contexts. International Journal of Science Education, 28(9), 1063-1086.

Ciolan, L., \& Ciolan, L. E. (2014). Two perspectives, same reality? How authentic is learning for students and for their teachers. Procedia - Social and Behavioural Sciences, 142, 24-28.

Davies, T., \& Gilbert, J. (2003). Modelling: Promoting creativity while forging links between science education and design and technology education. Canadian Journal of Science, Mathematics and Technology Education, 3(1), 67-82.

de Vries, M. J. (2001). The history of industrial research laboratories as a resource for teaching about science-technology relationships. Research in Science Education, 31(1), 15-28.

de Vries, M. J. (2013). Modeling in technology and engineering education. In P. J. Williams \& D. Gedera (Eds.), PATT 27, Technology Education for the Future: A Play on Sustainability, Christchurch, New Zealand, 2-6 December, 2013. Waikato: University of Waikato.

de Vries, M. J. (2017). Technology education: An international history. In M. J. de Vries (Ed.), Handbook of Technology Education. Dordrecht: Springer.

de Vries, M. J. (2018). The T and E in STEM: From promise to practice. In M. J. de Vries, S. Fletcher, S. Kruse, P. Labudee, M. Lang, I. Mammes, C. Max, D. Münk, B. Nicholl, J. Strobel, \& M. Winterbottom (Eds.), Research in technology education (pp. 11-19). Münster: Waxmann.

de Vries, M. J., \& Meijers, A. W. M. (2013). Beliefs, acceptances and technological knowledge. In M. J. de Vries, S. O. Hansson, \& A. W. M. Meijers (Eds.), Norms in technology (pp. 55-65). Dordrecht: Springer.

Diefes-Dux, H. A., Hjalmarson, M. A., Miller, T. K., \& Lesh, R. (2008). Model-eliciting activities for engineering education). In J. S. Zawojewski, H. Diefes-Dux, \& K. Bowman (Eds.), Models and Modeling in Engineering Education: Designing Experiences for All Students. Rotterdam: Sense Publishers. 
Feenberg, A. (2006). What is philosophy of technology? In J. Dakers (Ed.), Defining Technological Literacy: Towards an Epistemological Framework. New York: Palgrave.

Ferguson, E. S. (1992). Engineering and the mind's eye. Cambridge: MIT Press. Fox-Turnbull, W. (2006). The influences of teacher knowledge and authentic formative assessment on student learning in technology education. International Journal of Technology and Design Education, 16, 53-77.

France, B. (2018). Modeling in technology education: A route to technological literacy. In M. J. de Vries (Ed.), Handbook of Technology Education. Dordrecht: Springer.

France, B., Compton, V. J., \& Gilbert, J. K. (2011). Understanding modelling in technology and science: the potential of stories from the field. International Journal of Technology and Design Education, 21(3), 381-394.

Gilbert, J. (2004). Models and modelling: ROUTES to more authentic science education. International Journal of Science and Mathematics Education, 2(2), $115-130$

Gilbert, J. K., Boulter, C. J., \& Elmer, R. (2000). Positioning models in science education and in design and technology education. In J. K. Gilbert \& C. J. Boulter (Eds.), Developing Models in Science Education. Dordrecht: Kluwer Academic Publishers

Haglund, J., \& Strömdahl, H. (2012). Perspective on models in theoretical and practical traditions of knowledge: The example of Otto engine animations. International Journal of Technology and Design Education, 22(3), 311-327.

Hallström, J., \& Ankiewicz, P. (2019). Laying down the "T" and "E" in STEM education: Design as the basis of an integrated STEM philosophy. In S. Pulé \& M. J. de Vries (Eds.), Proceedings PATT 37: Developing a knowledge economy through technology and engineering education, 3-6 June 2019 University of Malta, Msida Campus (pp. 187-194). Msida: University of Malta.

Hansson, S. O. (2007). What is technological science? Studies in history and philosophy of science, 38(3), 523-527.

Hansson, S. O. (2013). What is technological knowledge? In I.-B. Skogh \& M. J. de Vries (Eds.), Technology Teachers as Researchers: Philosophical and Empirical Technology Education Studies in the Swedish TUFF Research School. Rotterdam: Sense Publishers.

Henderson, C., Connolly, M., Dolan, E. L., Finkelstein, N., Franklin, S., Malcom, S., Rasmussen, C., Redd, K., \& St. John, K. (2017). Towards the STEM DBER Alliance: why we need a discipline-based STEM education research community. International Journal of STEM Education, 4(14), 1-4.

Herrington, J., \& Parker, J. (2013). Emerging technologies as cognitive tools for authentic learning. British Journal of Educational Technology, 44(4), 607-615.

Herrington, J., Reeves, T., \& Oliver, R. (2010). A guide to authentic e-learning. New York: Routledge.

Ihde, D. (1993). Philosophy of Technology: An Introduction. New York: Paragon House.

Justi, R. S., \& Gilbert, J. K. (2002). Modelling, teachers' views on the nature of modelling, and implications for the education of modellers. International Journal of Science Education, 24(4), 369-387.

Kelley, T. R., \& Knowles, J. G. (2016). A conceptual framework for integrated STEM education. International Journal of STEM Education, 3(1), 11.

Kertil, M., \& Gurel, C. (2016). Mathematical modeling: A bridge to STEM education. International Journal of Education in Mathematics, Science and Technology, 4(1), 44-55.

Krell, M., \& Krüger, D. (2017). University students' meta-modelling knowledge. Research in Science \& Technological Education, 35(3), 261-273.

Lesh, R. (1981). Applied mathematical problem solving. Educational Studies in Mathematics, 12(2), 235-264

Lesh, R., Amit, M., \& Schorr, R. Y. (1997). Using "real-life" problems to prompt students to construct conceptual models for statistical reasoning. In The assessment challenge in statistics education (pp. 65-83). IOS Press.

Lesh, R., English, L., Sevis, S., \& Riggs, C. (2013). Modeling as a means for making powerful ideas accessible to children at an early age. In S. J. Hegedus \& J. Roschelle (Eds.), The SimCalc Vision and Contributions (pp. 419-436). Dordrecht: Springer

Lesh, R., Post, T., \& Behr, M. (1987). Representations and translations among representations in mathematics learning and problem solving. In C. Janvier (Ed.), Problems of Representation in the Teaching and Learning of Mathematics (pp. 33-40). Hillsdale: Lawrence Erlbaum Associates.

Margot, K. C., \& Kettler, T. (2019). Teachers' perception of STEM integration and education: A systematic literature review. International Journal of STEM Education, 6(2), 1-16.

Mitcham, C. (1994). Thinking through technology: The path between engineering and philosophy. Chicago: University of Chicago Press.
Müller, R. (2009). The notion of a model: A historical overview. In A. Meijers (Ed.), Philosophy of technology and engineering sciences (pp. 637-664). Burlington: North Holland.

Murphy, P., Lunn, S., \& Jones, H. (2006). The impact of authentic learning on students' engagement with physics. The Curriculum Journal, 17(3), 229-246.

Nia, M. G., \& de Vries, M. J. (2017). Models as artefacts of a dual nature: a philosophical contribution to teaching about models designed and used in engineering practice. International Journal of Technology and Design Education, 27(4), 627-653.

Niss, M. (2012). Models and modelling in mathematics education. Ems Newsletter, $86,49-52$.

Peterman, K., Daugherty, J. L., Custer, R. L., \& Ross, J. M. (2017). Analysing the integration of engineering in science lessons with the Engineering-Infused Lesson Rubric. International Journal of Science Education, 39(14), 1913-1931.

Pitt, J. (2009). Blurring the boundaries - STEM education and education for sustainable development. Design and Technology Education: An International Journal, 14(1), 37-48.

Radloff, J., \& Guzey, S. (2016). Investigating preservice STEM teacher conceptions of STEM education. Journal of Science Education \& Technology, 25, 759-774.

Rau, M. A. (2017). Conditions for the effectiveness of multiple visual representations in enhancing STEM learning. Educational Psychology Review, 29(4), 717-761.

Ropohl, G. (1997). Knowledge types in technology. International Journal of Technology and Design Education, 7, 65-72.

Roth, W.-M. (1995). Authentic school science: Knowing and learning in open-inquiry science laboratories. Dordrecht: Kluwer Academic Publishers.

Sanders, M. (2009). STEM, STEM Education, STEMmania. The Technology Teacher, $20-26$.

Schwarz, C. V., et al. (2009). Developing a learning progression for scientific modeling: Making scientific modeling accessible and meaningful for learners. Journal of Research in Science Teaching, 46(6), 632-654.

Scriven, M. (1988). Explanations, predictions, and laws. In J. C. Pitt (Ed.), Theories of explanation (pp. 51-74). New York: Oxford University Press.

Svärd, J., Schönborn, K., \& Hallström, J. (2017). Design of an authentic innovation project in Swedish upper secondary technology education. Australasian Journal of Technology Education, 4, 1-15. https://doi.org/10.15663/ajte.v4i1.48.

Tang, K.-S., \& Williams, P. J. (2018). STEM literacy or literacies? Examining the empirical basis of these constructs. Review of Education. https://doi.org/10. 1002/rev3.3162.

Turnbull, W. (2002). The place of authenticity in technology in the New Zealand curriculum. International Journal of Technology and Design Education, 12(1), 23-40.

Vincenti, W. G. (1990). What engineers know and how they know it. Baltimore: Johns Hopkins University Press.

Vos, P. (2011). What is 'authentic' in the teaching and learning of mathematical modelling? In G. Kaiser et al. (Eds.), Trends in teaching and learning of mathematical modelling (pp. 713-722). Dordrecht: Springer.

Williams, J. (2011). STEM Education: Proceed with caution. Design and Technology Education: An International Journal, 16(1), 26-35.

Williams, J. (2017). The Vocational Goals of STEM Education: Is that enough? Paper presented at PATT 2017. Philadelphia: Technology \& Engineering Education Fostering the Creativity of Youth Around The Globe 10-14 July 2017.

Zawojewski, J. S., Hjalmarson, M. A., Bowman, K. J., \& Lesh, R. (2008). A modeling perspective on learning and teaching in engineering education. In J. S. Zawojewski, H. Diefes-Dux, \& K. Bowman (Eds.), Models and Modeling in Engineering Education: Designing Experiences for All Students. Rotterdam: Sense Publishers.

\section{Publisher's Note}

Springer Nature remains neutral with regard to jurisdictional claims in published maps and institutional affiliations. 